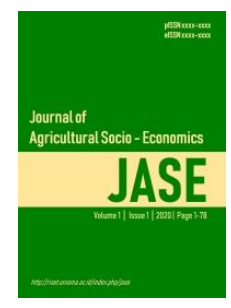

Journal of Agricultural Socio-Economics (JASE)

eISSN 2745-6897 | pISSN 2745-6889

Volum 2 Issue 1 (2021) Page 17-24

DOI:http://dx.doi.org/10.33474/jase.v1i2.13036

Submit: 11-01-2021 | Accepted: 18-03-2021 | Publish: 27-03-2021

\title{
Efisiensi Pemasaran Sapi Potong di Kecamatan Takisung Kabupaten Tanah Laut Provinsi Kalimantan Selatan
}

\author{
Yusuf Azis*, Ibnu Husin \\ Universitas Lambung Mangkurat, Kalimantan Selatan \\ *E-mail:yazisunlam@gmail.com
}

\begin{abstract}
Takisung District is one of the centers for beef cattle in Tanah Laut Regency. In creating an efficient and profitable marketing system for both farmers and consumers, farmers must choose short marketing channels. This study aims to identify the shape of the beef cattle marketing channel, determine the costs, benefits, margins, and farmer's share, and the marketing efficiency received by beef cattle producers. This research was conducted in Takisung District, Tanah Laut Regency. The sample villages were chosen deliberately, namely the three villages with the highest number of farmers (Source Makmur Village, Takisung Village, and Gunung Makmur Village). The sample of farmer respondents in each village was chosen randomly in proportion, with a total sample of 30 farmers. To select local traders and cutting traders, the snowball sampling method was used. The study was conducted from March to May 2020. The results showed that there were 4 forms of beef cattle marketing channels, namely Channel I (breeders - consumers), Channel II (breeders - slaughterers-consumers), Channel III (breeders - local traders - consumers), and Channel IV (breeders - local traders - slaughterers - consumers). Furthermore, costs, profits, margins, and farmer's share per head of cattle as well as marketing efficiency for each marketing channel, namely channel 1 with costs, profits, and marketing margins of Rp.0 and farmer's share get $100 \%$ results. Channel 2 with a cost of Rp. 570,000, a profit of Rp. 4,950,000 and a margin of Rp. 5,520,000 and a farmer's share with a yield of 73.74\%. Furthermore, channel 3 with a cost of Rp.243,000, a profit of Rp.457,000, and a margin of Rp.700,000, and farmer's share obtained a yield of $95.39 \%$. Finally, channel 4 with a cost of Rp. 1,766,000, a profit of Rp. 5,124,000 and a margin of Rp. 5,920,000 and farmer's share getting 71.84\% results. Economically, beef cattle marketing can be said to be relatively efficient in all marketing channels. The most efficient marketing channels are channel 1 and channel 3.
\end{abstract}

Keywords: Marjin pemasaranfarmer's share,Efisiensi pemasaran

Abstrak. Kecamatan Takisung merupakan salah satu sentra sapi potong di Kabupaten Tanah Laut. Dalam menciptakan sistem pemasaran yang efisien serta menguntungkan baik peternak maupun konsumen, maka peternak harus memilih saluran pemasaran yang pendek. Penelitian ini bertujuan untuk mengidentifikasi bentuk saluran pemasaran sapi potong., mengetahui biaya, keuntungan, marjin dan farmer's share serta efisiensi pemasaran yang diterima produsen sapi potong. Penelitian ini dilaksanakan Kecamatan Takisung Kabupaten Tanah Laut. Sampel desa dipilih secara sengaja, yaitu tiga desa yang terbanyak peternaknya (Desa Sumber Makmur, Desa Takisung dan Desa Gunung Makmur). Sampel responden peternak pada masing-masing desa dipilih secara acak terproporsi, dengan total sampel 30 peternak. Untuk memilih pedagang lokal dan pedagang pemotong digunakan metode snowball sampling. Penelitian pada bulan Maret hingga Mei 2020. Hasil penelitian menunjukkan ada 4 bentuk saluran pemasaran ternak sapi potong, yaitu Saluran I (peternak - konsumen), Saluran II (peternak - pedagang pemotong-konsumen), Saluran III (peternak - pedagang lokal - konsumen) dan Saluran IV (peternak - pedagang lokal - pedagang pemotong - konsumen). Selanjutnya Biaya, keuntungan, marjin dan farmer's share per ekor sapi serta efisiensi pemasaran untuk masing-masing saluran pemasaran yaitu saluran 1 dengan biaya, keuntungan, dan marjin pemasaran Rp.0 dan farmer's share memperoleh hasil 100\%. Saluran 2 dengan biaya Rp.570.000, keuntungan Rp.4.950.000 dan marjin Rp.5.520.000 serta farmer's share memperoleh hasil 73,74\%. Selanjutnya saluran 3 dengan biaya Rp.243.000, keuntungan Rp.457.000 dan marjin Rp.700.000 serta farmer's share memperoleh hasil 95,39\%. Terakhir saluran 4 dengan biaya Rp.1.766.000, keuntungan Rp.5.124.000 dan marjin Rp.5.920.000 serta farmer's share memperoleh hasil 71,84\%. Secara ekonomi, pemasaran sapi potong dapat dikatakan relatif sudah efisien pada semua saluran pemasaran. Saluran pemasaran yang relatif paling efisien adalah saluran 1 dan saluran.

Kata Kunci: Biaya pemasaran, Keuntungan pemasaran

Page 17 of 24 I Journal of Agricultural Socio-Economics (JASE) 


\section{PENDAHULUAN}

Sektor peternakan merupakan salah sektor unggulan di Kalimantan Selatan yang terus didorong untuk dikembangkan, sehingga Kalimantan Selatan mampu menjadi daerah penyedia ternak. Berbagai upaya dilakukanpemerintah untuk meningkatkan populasi dan produksi ternak, ketersediaan pakan, hingga memberdayakan sumber daya manusia di bidang peternakan menjadi mandiri untuk menghadirkan produk unggulan yang berdayasaing di pasar domestik dan global (Dinas Peternakan Kabupaten Tanah Laut, 2017).

Populasi ternak besar yang terdiri dari sapi, kerbau dan kuda tersebar di seluruh kabupaten/kota di Kalimantan Selatan. Tahun 2013, populasi sapi sebanyak 132.003 ekor (terdiri dari sapi potong sebanyak 131.733 ekor dan sapi perah sebanyak 270 ekor), kerbau sebanyak 23.764 ekor dan kuda sebanyak 99 ekor. Produksi daging tahun 2013 untuk ternak besar sebanyak $10.597 .150 \mathrm{~kg}$, yang terdiri dari daging sapi sebanyak $9.766 .111 \mathrm{~kg}$, daging kerbau sebanyak $824.781 \mathrm{~kg}$ dan daging kuda sebanyak $6.258 \mathrm{~kg}$ (Badan Pusat Statistik, 2017). Usaha perdagangan sapi potong memilik jumlah terbesar di Kalimantan Selatan.

Data Dinas Peternakan Kabupaten Tanah Laut, Kalimantan Selatan, Tanah Laut penghasil sapi terbesar di Kalimantan Selatan, jika dibandingkan dengan kabupaten/kota lain. perkembangan populasi sapi potong di Kabupaten Tanah Laut per kecamatan antara tahun 2014 sampai 2018 terus meningkat dari tahun ke tahun. Melihat kenyataannya yang ada Kabupaten Tanah Laut memiliki potensi yang cukup besar untuk pengembangan sapi di Kalimantan Selatan. Salah satu sentranya yaitu terdapat di Kecamatan Takisung.

Usaha perdagangan sapi potong di Indonesia khususnya yang menyangkut saluran pemasaran sapi potong belum banyak diatur oleh pemerintah. Usaha pemasaran sapi potong lebih banyak dikuasai oleh lembaga-lembaga pemasaran yang mempunyai skala usaha besar seperti "blantik" (penjual sapi), pedagang pengumpul dan jagal. Masing masing jalur pemasaran mempunyai peran dan fungsi tersendiri dalam proses pemasaran. Saluran pemasaran dapat dikatakan sebagai saluran atau jalur yang digunakan baik secara langsung maupun tidak langsung kepada konsumen, untuk memudahkan pemindahan suatu produk bergerak dari produsen sampai berada di tangan konsumen.

Dalam menciptakan sistem pemasaran yang efisien serta menguntungkan baik peternak maupun konsumen, maka peternak harus memilih saluran pemasaran yang pendek. Adanya lembaga - lembaga pemasaran yang membantu pemindahan suatu produk maka akan dapat diketahui berapa margin yang diperoleh pada setiap lembaga pemasaran. Banyaknya lembaga - lembaga pemasaran yang terlibatmengakibatkan semakin panjang saluran pemasaran dan semakin besar margin pemasarannya.

\subsection{Lokasi dan Waktu Penelitian}

Penelitian dilaksanakan di Kecamatan Takisung Kabupaten Tanah Laut Provinsi Kalimantan Selatan. Lokasi penelitian ini merupakan tempat populasi sapi potong terbanyak di Kabupaten Tanah Laut setelah Kecamatan Pelaihari. Penelitian ini dilaksanakan pada bulan Maret hingga Mei 2020.

\subsection{Jenis dan Sumber Data}

Metode yang dilakukan dalam penelitian ini adalah metode survei dan pengamatan langsung di lapangan serta mengadakan wawancara dengan menggunakan kuesioner kepada masing- masing responden. Data primer yang dikumpulkan dari responden peternak meliputi identitas peternak, sistem penjualan dan harga jual ternak, untuk responden pedagang perantara meliputi identitas pedagang perantara, jumlah pembelian, harga pembelian dan penjualan ternak, biaya pemasaran dan cara pembayaran, sedangkan responden konsumen akhir atau pedagang daging meliputi identitas pedagang daging harga pembelian ternak dan harga penjualan daging sapi.Data sekunder diperoleh dari Dinas Peternakan, Badan Pusat Statistik Kabupaten Tanah Laut serta literatur yang ada kaitannya dengan penelitian ini.

\subsection{Metode Penentuan Responden}

Dari 12 desa yang ada di Kecamatan Takisung dipilih secara sengaja tiga desa yang paling banyak jumlah peternaknya yaitu Desa Takisung, Gunung Makmur, dan Sumber Makmur. Jumlah populasi di 3 desa tersebut adalah 65 orang. Menurut Arikunto (1996) karena jumlah populasi kurang dari 100 maka sampel peternak yang diambil adalah sebanyak 30 orang.

Adapun pengambilan contoh peternak di tiap desa dilakukan secara acak terproporsi sebagai berikut:

1. Sumber Makmur 21/65 x $30=10$ peternak. 
2. Takisung $23 / 65 \times 30=10$ peternak.

3. Gunung Makmur 21/65 x $30=10$ peternak.

Untuk memilih pedagang lokal dan pedagang pemotong digunakan metode snowball sampling yaitu teknik pengambilan data dari peternak yang menjadi sumber informasi tentang pedagang pengumpul dan pedagang lainnya yang dominan yang dijadikan contoh.

\subsection{Analisis Data}

Untuk mengidentifikasi tujuan pertama yaitu mengetahui saluran dan lembaga pemasaran ternak sapi potong dilakukan dengan cara menelusuri mata rantai saluran pemasaran yang dilalui di tingkat petani sampai dengan konsumen akhir.

untuk menjawab tujuan kedua yaitu menganalis berapa biaya pemasaran menggunakan rumus:

$\mathrm{Bp}=\mathrm{Bp} 1+\mathrm{Bp} 2+\mathrm{Bp} 3+\ldots .+\mathrm{Bpn}$

dengan:

$\mathrm{Bp} \quad$ biaya pemasaran sapi (Rp)

$\mathrm{Bp} 1, \ldots \mathrm{Bpn} \quad$ biaya pemasaran sapi tiap-tiap lembaga pemasaran sapi (Rp)

$1,2,3, \ldots \mathrm{n} \quad$ jumlah lembaga

keuntungan pemasaran sapi dapat dihitung dengan menggunakan rumus sebagai berikut:

$\mathrm{Kp}=\mathrm{Kp} 1+\mathrm{Kp} 2+\mathrm{Kp} 3+\ldots .+\mathrm{Kpn}$

dengan:

$\mathrm{Kp} \quad$ keuntungan pemasaran sapi (Rp)

$\mathrm{Kp} 1, \mathrm{Kpn} \quad$ keuntungan pemasaran tiap lembaga pemasaran sapi (Rp)

Marjin pemasaran untuk selisih harga ditingkat produsen dan tingkat konsumen menggunakan rumus:

$\mathrm{Mp}=\mathrm{Pr}-\mathrm{Pf}$

dengan:

$\mathrm{Mp} \quad$ margin pemasaran sapi (Rp/ekor)

Pr harga sapi ditingkat konsumen (Rp./ekor)

Pf Harga sapi yang diterima produsen (Rp./ekor)

Margin yang diperoleh pedagang perantara dari sejumlah biaya pemasaran yang dikeluarkan dan keuntungan yang diterima oleh pedagang perantara yang dirumuskan:

$\mathrm{Mp}=\mathrm{Bp}+\mathrm{Kp}$ dengan:

Mp margin pemasaran sapi (Rp/ekor)

Bp Biaya pemasaran sapi (Rp./ekor)

Kp Keuntungan pemasaran sapi (Rp./ekor)

Bagian yang diterima produsen (farmer's share). Menurut Sudiyono (2002), bagian yang diterima petani (farmer's share) sama dengan harga yang betul-betul diterima dibagi dengan harga yang dibayarkan oleh konsumen dikalikan $100 \%$.

$\mathrm{F}=(\mathrm{Pf} / \mathrm{Pr}) \times 100 \%$

\section{Keterangan:}

F Bagian yang diterima peternak sapi (farmer's share);

Pf Harga ditingkat peternak sapi;

Pr Harga ditingkat konsumen.

Tujuan ketiga untuk menentukan efisiensi pemasaran secara ekonomi dapat diketahui dari besarnya bagian yang diterima produsen (farmer's share). Pemasaran sapi dianggap efisien secara ekonomis apabila pada saluran pemasarannya bagian yang diterima produsen (farmer's share) 
mempunyai nilai tinggi. Menurut Cahyono et al (2013), bila bagian yang diterima produsen $>50 \%$ maka pemasaran dikatakan efisien, dan bila bagian yang diterima produsen $\leq 50 \%$ berarti pemasaran belum efisien.Selain itu juga untuk efisiensi pemasaran sapi potong dapat dilakukan analisis efisiensi ekonomi yang menggunakan rumus sebagai berikut (Sudiyono, 2002 dan Anindita, 2004) :

$$
\mathrm{EpE}=(\mathrm{C} / \mathrm{H}) \times 100 \%
$$

$$
\begin{aligned}
& \text { Keterangan : } \\
& \mathrm{EpE}=\text { Efisensi ekonomis pemasaran (\%) } \\
& \mathrm{C}=\text { Total biaya pemasaran }(\mathrm{Rp}) \\
& \mathrm{H} \text { = Harga jual di konsumen akhirr(Rp) }
\end{aligned}
$$

Efisiensi ekonomis terjadi jika biaya pemasaran dapat ditekan sehingga keuntungan tinggi, persentase perbedaan harga yang dibayarkan konsumen dan produsen tidak terlalu tinggi dan adanya kompetisi pasar yang sehat. Sehingga pada hubungan rumus di atas saluran pemasaran yang lebih efisien adalah pada saluran pemasaran yang mempunyai nilai efisiensi yang paling kecil

\section{HASIL DAN PEMBAHASAN}

\subsection{Saluran Pemasaran dan Fungsi Pemasaran}

Saluran Pemasaran. Saluran pemasaran adalah penyaluran sapi potong dari peternak produsen ke konsumen akhir, dan yang menyelenggarakannya berupa lembaga atau badan- badan yang bertugas melaksanakan fungsi pemasaran itu sendiri atau memenuhi keinginan konsumen semaksimal mungkin. Sedangkan pihak konsumen akan memberikan imbalan berupa marjin kepada lembaga pemasaran tersebut. Dari hasil survei menunjukkan bahwa aktivitas pemasaran ternak sapi potong di Kecamatan Takisung Kabupaten Tanah Laut dijalankan melalui beberapa tipe saluran pemasaran yaitu:

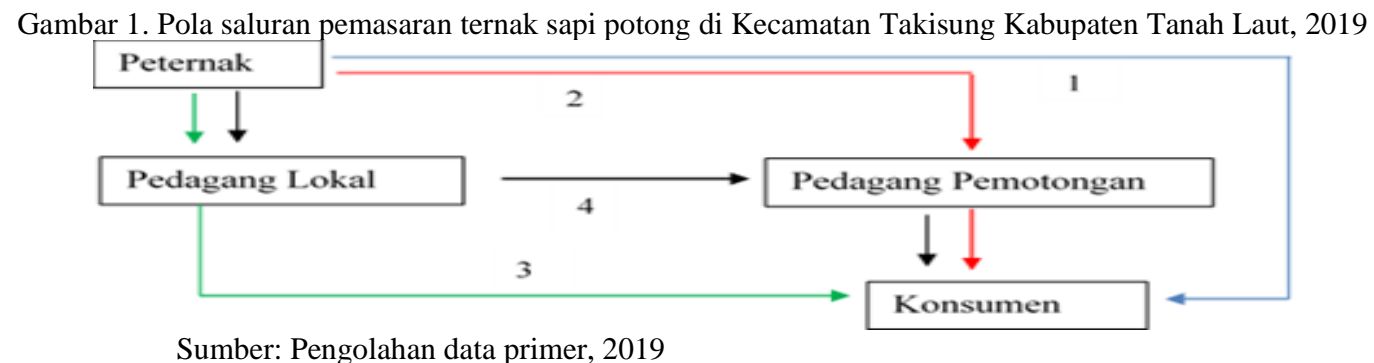

Berdasarkan hasil penelitian. Tiga komoditas berdasarkan gambar dapat dikaji bahwa saluran pemasaran ternak sapi potong di Kecamatan Takisung terdapat empat jenis saluran ternak sapi aluran pemasaran ternak sapi potong.

Saluran I (Peternak-Konsumen).Saluran Pertama adalah tipe saluran yang sederhana, dimana petani peternak langsung berhubungan dengan pasar atau konsumen tanpa perantara. Tipe ini hanya terjadi sewaktu peternak membutuhkan sesuatu untuk kebutuhan hidupnya. Penjualan ini dengan cara konsumen mendatangi peternak dan sebaliknya, penjualan itu dilakukan pada saat hari orang hendak melakukan perkawinan dan Hari Raya Qurban. Hari-hari biasa peternak kurang luas dalam mencari informasi sampai ke konsumen langsung.

Saluran II (Peternak-Pedagang Pemotong-Konsumen).Saluran kedua adalah tipe saluran pemasaran lokal di tingkat kecamatan, dimana peternak langsung menjual sapinya ke pedagang pemotong, dimana disini peternak sudah saling kenal atau sudah berlangganan.dan kemudian pedagang pemotong membawa ternak tersebut ke Rumah Penyembelihan Hewan (RPH), kemudian menjual ke konsumen dalam bentuk karkas. Dalam tipe saluran ini biaya pemasaran yang dikeluarkan oleh pedagang pemotong.

Saluran III (Peternak-Pedagang Lokal-Konsumen).Saluran ketiga adalah dimana peternak menjual sapi ke pedagang lokal, karena peternak tidak ingin mengeluarkan biaya. Pedagang lokal (blantik) menguasai proses pemasaran baik di desa maupun di pasar hewan, sehingga peternak tidak perlu membawa sapi ke pasar hewan. Biaya transportasi, parkir dan biaya tenaga kerja di keluarkan blantik. Blantik membawa sapi ke pasar hewan untuk dijual kembali. 
Saluran IV (Peternak-Pedagang Lokal-Pedagang Pemotong-Konsumen).Saluran keempat adalah tipe saluran pemasaran yang terdapat pada pasaran lokal baik di tingkat desa, kecamatan, dan kabupaten. Tipe saluran pemasaran ini petani peternak menjual langsung kepada pedagang lokal (blantik) kemudian menjual ternak kepada pedagang pemotong, dan para pedagang pemotong tersebut selanjutnya menjual ternak sapi kepada konsumen dalam bentuk daging atau karkas. Dalam saluran ini biaya yang dikeluarkan cuma dari pihak pedagang lokal (blantik) dan pedagang pemotong.

Fungsi Pemasaran. Hasil penelitian menunjukkan bahwa $10 \%$ peternak menjual ternak sapi potongnya kepada konsumen, $16,7 \%$ peternak menjual ternak sapi potongnya ke pedagang pemotong, kemudian dijual lagi kekonsumen dalam bentuk karkas. 43,3\% peternak menjual sapinya ke pedagang lokal (blantik) kemudian dijual lagi ke konsumen dan 30\% peternak menjual ternak sapi potongnya kepada peternak lokal (blantik) selanjutnya dijual lagi ke pedagang pemotong dan selanjutnya dipasarkan ke konsumen dalam bentuk karkas. Artinya sebagian besar peternakmenjual ternak sapinya ke pedagang lokal agar peternak tidak mengeluarkan biaya besar.

Pedagang lokal (blantik) yang melakukan pembelian ternak sapi dari peternak kemudian menjualnya ke pasar hewan pada hari pasar. Skala usaha pedagang lokal berkisar antara 2 -

3 ekor setiap kali melakukan pemasaran. Pedagang pemotong melakukan pembelian ternak sapi di pasar hewan kemudian memotongnya di RPH setempat. Setiap hari pasar pedagang pemotong melakukan pembelian ternak sapi sebanyak 3 - 5 ekor, kemudian memotongnya setiap hari 1-3 ekor. Ternak sapi yang dipilih pedagang pemotong untuk dipotong yaitu sapi yang memiliki rata rata berat hidup $275 \mathrm{~kg}$. Sapi yang telah dipotong kemudian diangkut menuju pasar menggunakan kendaraan dan dipasarkan dengan menyewa kios yang ada di pasar.

Setiap lembaga pemasaran melakukan fungsi- fungsi pemasaran dalam kaitannya dengan kegiatan usaha memasarkan ternak sapi potong. Fungsi-fungsi pemasaran meliputi fungsi pertukaran, fungsi fisik, dan fungsi fasilitas. Untuk mengetahui fungsi-fungsi pemasaran yang terjadi di tingkat petani peternak dan pedagang sapi potong, dapat dilihat pada Tabel 1 .

\begin{tabular}{|c|c|c|c|}
\hline $\begin{array}{c}\text { Fungsi Fungsi } \\
\text { Pemasaran }\end{array}$ & $\begin{array}{l}\text { Petani/ } \\
\text { Peternak }\end{array}$ & $\begin{array}{l}\text { Pedagang } \\
\text { Lokal }\end{array}$ & $\begin{array}{l}\text { Pedagang } \\
\text { Pemotong }\end{array}$ \\
\hline \multicolumn{4}{|l|}{$\overline{\text { Pertukaran }}$} \\
\hline 1. Pembelian & & $*$ & $*$ \\
\hline \multicolumn{4}{|l|}{ Fisik } \\
\hline 1. Penampungan & $*$ & $*$ & $*$ \\
\hline 2. Pengangkutan & & $*$ & $*$ \\
\hline 3. Pengemasan & & & $*$ \\
\hline \multicolumn{4}{|l|}{ Fasilitas } \\
\hline 1. Penanggungan Resiko & & $*$ & $*$ \\
\hline 2. Pembiayaan & & $*$ & $*$ \\
\hline 3. Informasi Pasar & $*$ & $*$ & $*$ \\
\hline
\end{tabular}

Sumber: Pengolahan data primer, 2020

\subsection{Analisis Biaya dan Marjin Pemasaran}

Setiap lembaga pemasaran berusaha untuk mendapatkan keuntungan dari kegiatan usahanya dengan meningkatkan nilai guna dari ternak sapi potong seperti guna waktu, guna tempat, guna bentuk dan guna pemilikan. Untuk mendapatkan tambahan nilai guna tersebut,setiap lembaga pemasaran mengeluarkan biaya pemasaran, seperti biaya pengangkutan, biaya pakan dan biaya tenaga kerja.

Saluran I.Pada saluran 1, biaya pemasaran yang dikeluarkan tidak ada karena peternak langsung menjual ternaknya ke konsumen tanpa perantara. Berat sapi potong pada saluran ini rata-rata memiliki bobot hidup $250 \mathrm{~kg}$. Dalam hal ini konsumen lebih diuntungkan jika langsung membeli ternak sapinya kepada peternak. Jika dilihat dari Tabel 2, tidak ada marjin dan keuntungan pemasaran di saluran ini dikarenakan peternak menerima 100\% dari bagian harga yang dibayarkan konsumen.

Tabel 2. Biaya, keuntungan, dan marjin pemasaran serta farmer's share pada saluran 1

\begin{tabular}{lll} 
No. & Uraian biaya & Rp./ekor \\
\hline 1. & Peternak & \\
& a. Harga jual & 14.600 .000
\end{tabular}




\begin{tabular}{llr}
2. & Konsumen & \\
& a. Harga beli & 14.600 .000 \\
3. & Margin pemasaran & 0 \\
4. & Keuntungan pemasaran & 0 \\
5. & Farmer's share & $100 \%$ \\
\hline
\end{tabular}

Sumber: Pengolahan Data Primer, 2020

Saluran2. Pada saluran 2 ini biaya apa saja yang dikeluarkan, berapa keuntungan yang diperoleh dan marjin pemasaran serta farmer's share dapat dilihat dari Tabel 3.

\begin{tabular}{|c|c|c|c|c|}
\hline No. & \multicolumn{3}{|l|}{ Uraianbiaya } & $\underline{\mathrm{Rp}} . / \mathrm{ekor}$ \\
\hline \multirow[t]{2}{*}{1.} & \multicolumn{3}{|l|}{ Peternak } & \\
\hline & \multicolumn{3}{|l|}{ Harga jual } & 15.500 .000 \\
\hline \multirow[t]{21}{*}{2.} & \multicolumn{3}{|c|}{ Pedagang pemotong } & \\
\hline & \multicolumn{3}{|c|}{ Harga beli } & 15.500 .000 \\
\hline & \multicolumn{4}{|l|}{ Biaya } \\
\hline & \multicolumn{3}{|c|}{ a. Biaya angkut } & 150.000 \\
\hline & \multicolumn{3}{|c|}{ b. Biaya tenaga kerja } & 100.000 \\
\hline & \multicolumn{3}{|c|}{ c. Sewa kios } & 250.000 \\
\hline & \multicolumn{3}{|c|}{$\begin{array}{l}\text { d. Retribusi Rumah Potong Hewan } \\
\text { (RPH) }\end{array}$} & 20.000 \\
\hline & \multicolumn{3}{|c|}{ e. Parkir } & - \\
\hline & \multicolumn{3}{|l|}{ f. Biaya lainnya } & 50.000 \\
\hline & & Total & biaya & 570.000 \\
\hline & \multicolumn{4}{|c|}{ Harga penjualan dalam bentuk } \\
\hline & \multicolumn{4}{|c|}{ Karkas } \\
\hline & Uraian karkas & $\begin{array}{l}\text { Harga per } \\
\text { Kg }\end{array}$ & $\begin{array}{l}\text { Jumlah } \\
\mathrm{Kg}\end{array}$ & Total \\
\hline & a. Daging & 130.000 & 113 & 14.690 .000 \\
\hline & b. Kulit & 15.000 & 20 & 300.000 \\
\hline & c. Kepala & 25.000 & 8 & 200.000 \\
\hline & d. Ekor & 60.000 & 3 & 180.000 \\
\hline & e. Hati & 80.000 & 5 & 400.000 \\
\hline & f.Jeroan & 70.000 & 15 & 1.050 .000 \\
\hline & g. Tulang/Iga & 70.000 & 60 & 4.200 .000 \\
\hline & Total & & 224 & $\begin{array}{l}21.020 .00 \\
0\end{array}$ \\
\hline \multirow[t]{2}{*}{3} & Konsumen & & & \\
\hline & Harga beli & & & $\begin{array}{l}21.020 .00 \\
0\end{array}$ \\
\hline 4 & $\begin{array}{l}\text { Marjin } \\
\text { pemasaran }\end{array}$ & & & 5.520 .000 \\
\hline 5 & $\begin{array}{l}\text { Keuntunganpe } \\
\text { masaran }\end{array}$ & & & 4.950 .000 \\
\hline 6 & Farmer's share & & & $73,74 \%$ \\
\hline
\end{tabular}

Sumber: Pengolahan data primer, 2020

Berdasarkan Tabel 3, diketahui pada saluran 2 memiliki total biaya Rp.570.000/ekor, keuntungan sebesar Rp.4.950.000/ekor dan memiliki marjin pemasaran Rp.5.520.000/ekor serta memperoleh hasil farmer's share $73,74 \%$.

Saluran 3. Untuk mengetahui berapa biaya yang dikeluarkan, keuntungan yang dihasilkan dan marjin serta farmer's share pada saluran 3 ini, dapat dilihat dari Tabel 4. Dapat dilihat pada Tabel 4, bahwa total biaya yang dikeluarkan pada saluran ini adalah Rp. 243.000/ekor dan memperoleh hasil keuntungan sebesar Rp. 457.000/ekor dan memiliki marjin sebesar Rp. 700.000/ekor serta memperoleh hasil farmer's share $95,39 \%$.

Tabel 4. Biaya, keuntungan, dan marjin pemasaran serta farmer's share pada saluran 3

\begin{tabular}{clc}
\cline { 1 - 1 } No. & Uraianbiaya & Rp./ekor \\
2. & $\begin{array}{l}\text { Peternak } \\
\text { Harga jual }\end{array}$ & 14.500 .000 \\
& $\begin{array}{l}\text { Pedagang lokal (blantik) } \\
\text { Harga beli }\end{array}$ & 14.500 .000
\end{tabular}




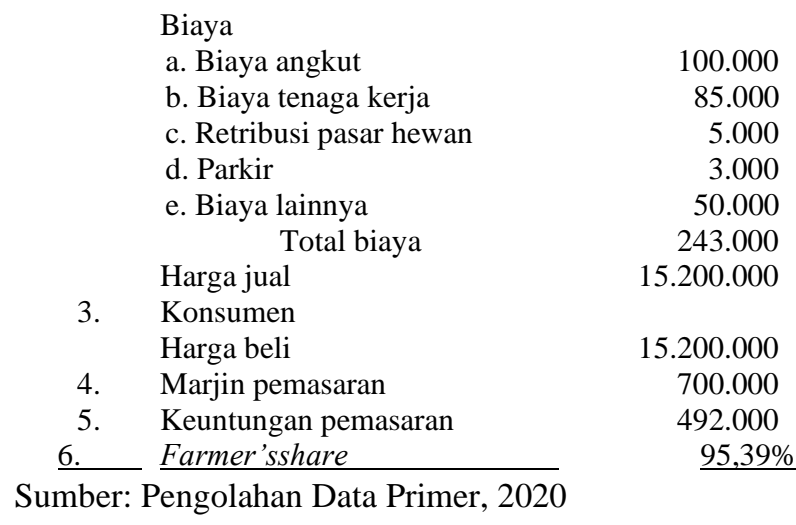

Saluran 4.Untuk mengetahui apa saja biaya yang dikeluarkan, seberapa banyak keuntungan dan margin pemasaran di tiap pedagang seta farmer's share dapat dilihat pada Tabel 5. Dari Tabel 5 terlihat total biaya yang dikeluarkan olehsebesar Rp.523.000/ekor, maka total keseluruhan dari biaya pedagang lokal dan biaya pedagang pemotong sebesar Rp.766.000/ekor. Kemudian keuntungan yang diperoleh pedagang lokal sebesar Rp.457.000/ekor dan keuntungan yang diperoleh pedagang pemotong sebesar Rp.4.697.000/ekor, maka total keseluruhan dari ke dua pedagang tersebut adalah Rp.5.124.000/ekor. Sedangkan untuk marjin pemasaran dari pedagang lokal (blantik) adalah Rp.700.000/ekor dan pedagang pemotong adalah Rp.5.220.000/ekor, maka total keseluruhan margin keduanya adalah Rp.5.920.000/ekor serta memperoleh hasil farmer's share sebanyak $71,86 \%$.

\subsection{Analisis Efisiensi Pemasaran Sapi Potong}

Efisiensi pemasaran secara ekonomi dapat diketahui dari besarnya bagian yang diterima produsen (farmer's share). Menurut Cahyono et al (2013), bila bagian yang diterima produsen

$>50 \%$ maka pemasaran dikatakan efisien, dan bila bagian yang diterima produsen $\leq 50 \%$ berarti pemasaran belum efisien. Hasil penelitian ini menunjukkan farmer's share pada semua saluran pemasaran $>50 \%$ (efisien), dimana dari yang relatif paling efisien adalah saluran 1 (farmer's share $=100 \%)$, diikutisaluran $3(95,39 \%)$, saluran $2(73,74 \%)$ dansaluran $4(71,86 \%)$

Cara untuk mengetahui efisiensi ekonomis adalah dengan menghitung total biaya pemasaran dibagi nilai total produk dikali 100\%. Berdasarkan perhitungan yang telah dilakukan, Indeks efisiensi ekonomis dari yang relative paling efisienadalah saluran pemasaran $1(0 \%)$,saluran $3(1,60 \%)$,saluran $2(2,71 \%)$ dan saluran $4(3,64 \%)$.

\section{KESIMPULAN}

Berdasarkan hasil penelitian dapat diambil kesimpulan sebagai berikut:

1. Ada 4 bentuk saluran pemasaran ternak sapi potong di daerah Kecamatan Takisung, yaituSaluran I yaitu (peternak - konsumen)., Saluran II yaitu (peternak - pedagang Pemotong)., Saluran III yaitu (peternak - pedagang lokal - konsumen) dan Saluran IV yaitu (peternak - pedagang lokal pedagang pemotong - konsumen).

2. Biaya, keuntungan, dan marjin pemasaran serta farmer's share per ekor untuk masing- masing saluran pemasaran yaitu saluran 1 dengan biaya, keuntungan, dan marjin pemasaran Rp.0 dan farmer's sharememperoleh hasil $100 \%$. Saluran 2 dengan biaya Rp.570.000, keuntungan Rp.4.950.000 dan marjin Rp.5.520.000 serta farmer's share memperoleh hasil $73,74 \%$. Selanjutnya saluran 3 dengan biaya Rp.243.000, keuntungan Rp.457.000 dan marjin Rp.700.000 serta farmer's share memperoleh hasil 95,39\%. Terakhir saluran 4 dengan biaya Rp.1.766.000, keuntungan Rp.5.124.000 dan marjin Rp.5.920.000 serta farmer's share memperoleh hasil $71,84 \%$.

3. Secara ekonomi, pemasaran sapi potong dapat dikatakan relatif sudah efisien pada semua saluran pemasaran. Saluran pemasaran yang relative paling efisien adalah saluran 1 dan saluran 3 .

\section{DAFTAR PUSTAKA}

Anindita, R. 2004. Pemasaran Hasil Pertanian. Papyrus : Surabaya.

Badan Pusat Statistik. 2017. Statistik Kabupaten Tanah laut. Badan Pusat Statistik. 
Cahyono, W, Kusnandar, dan Sri Marwanti. 2013. Analisis Efisiensi Pemasaran Sayuran Wortel di Sub Terminal Agribisnis 1. No $1: 1-20$

Dinas Peternakan Kabupaten Tanah Laut. 2017. Data Statistik Ternak Bersar Sapi Dan Kerbau Tahun 2017. Kabupaten Tanah Laut.

Hanafiah, A.M. dan A.M. Saefuddin. 1986. Tataniaga Hasil Pertanian. Penerbit UI. Jakarta.

Kotler, P. 1980.Marketing Management: Analysis, Planning, and Control. 4th Ed.London: PrenticeHall, Inc.

Soekartawi. 1993. Prinsip Dasar Manajemen Pemasaran Hasil - Hasil Pertanian. Rajawali Press. Jakarta Sudiyono, Armand. 2002. Pemasaran Pertanian. UMM Press. Malang 